\title{
Technoeconomic Analysis of Ducted Wind Turbines and Their Slow Acceptance on the Market
}

\author{
Peace-Maker Masukume, ${ }^{1}$ Golden Makaka, ${ }^{1}$ and David Tinarwo ${ }^{2}$ \\ ${ }^{1}$ Department of Physics, University of Fort Hare, Private Bag Box X1314, Alice 5700, South Africa \\ ${ }^{2}$ Department of Physics, University of Venda, Private Bag Box X5050, Thohoyandou 0950, South Africa \\ Correspondence should be addressed to Peace-Maker Masukume; pmasukume@ufh.ac.za
}

Received 17 June 2014; Revised 12 November 2014; Accepted 22 November 2014; Published 10 December 2014

Academic Editor: Jing Shi

Copyright (C) 2014 Peace-Maker Masukume et al. This is an open access article distributed under the Creative Commons Attribution License, which permits unrestricted use, distribution, and reproduction in any medium, provided the original work is properly cited.

\begin{abstract}
The encasing of wind turbines in a duct to enhance performance is not new. A ducted wind turbine produces more power than an unducted wind turbine of the same parameters. A number of approaches in studying the effects of diffusers and other wind concentrating devices have been done and have resulted in a number of prototypes produced but without any commercialization. The aim of this paper is to investigate the failure of commercialization of ducted turbines. A technical and economic analysis of a ducted turbine is also presented. The work shows that traditional economic methods used to evaluate ducted wind turbines are erroneous; they do not account for external effects of power generation and individual and community benefits derived from this technology. Failure to penetrate the market is due to negative publicity as a result of the erroneous evaluation undertaken and lack of appropriate engineering techniques to protect ducted wind energy systems in extreme wind conditions.
\end{abstract}

\section{Introduction}

The quest for sustainable and environmentally friendly methods of electric generation and the oil crisis experienced in late 1973 have fueled the shift to renewable energy sources. This has seen a tremendous growth in renewable energy technologies. Global power capacity from renewables increased by $75 \%$ between 2004 and 2008 [1]. The total power capacity from renewables as in 2008 was $280 \mathrm{GW}$ and of this $121 \mathrm{GW}$ is from wind power. Wind power has been the fastest growing renewable energy sector. This exponential growth in wind power is a result of its low cost which is relatively low when compared with other renewable energy sources [2].

South Africa's energy intensive economy depends greatly on fossil fuels for energy generation and consumption with almost $90 \%$ coal based electricity generation and is ranked among the top 20 emitters of greenhouse gasses in the world and as the largest emitter in Africa [3]. However, South Africa is endowed with abundant renewable resources. Besides the vast solar resource characteristic, South Africa has more than a thousand kilometer long coastline with abundant wind resource potential. The wind speeds along the coastline are greater than or equal to $4 \mathrm{~m} / \mathrm{s}$ at $10 \mathrm{~m}$ and $8,5 \mathrm{~m} / \mathrm{s}$ at $50 \mathrm{~m}$.
The rest of the country is characterized by wind speeds between 3 and $4 \mathrm{~m} / \mathrm{s}$ and further north wind speeds are as low as less than $3 \mathrm{~m} / \mathrm{s}$ [4]. Most rural locations are situated in these low wind speed areas and in most cases have no access to national grid electricity. Supplies of other nonrenewable sources of energy are also either unavailable, unreliable, or, for many, too expensive [5].

It is from this background that the use of power augmentation devices becomes necessary to exploit low wind speeds and thus meet electrical needs of most rural people. The encasing of wind turbines in a duct or "shroud" in order to enhance their performance dates back to the 1950s [6], when it was recognized that a shroud augmented wind turbine can produce up to twice the power of unshrouded turbine of the same diameter. Research work in this field has taken a number of approaches in studying the effects of diffusers and other wind concentrating devices [7]. Varied conclusions were drawn from these studies with some claiming that the Betz limit can be surpassed with a ducted wind turbine [8]. Some substantial amount of research has been done with regard to diffusers and other concentrating devices but without any commercial success [9]. Several prototypes have been developed but according to Phillips [10] the addition 


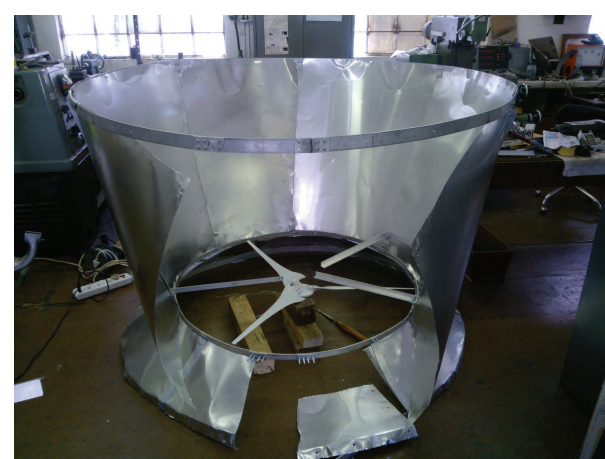

FIGURE 1: DSWES shroud under construction.

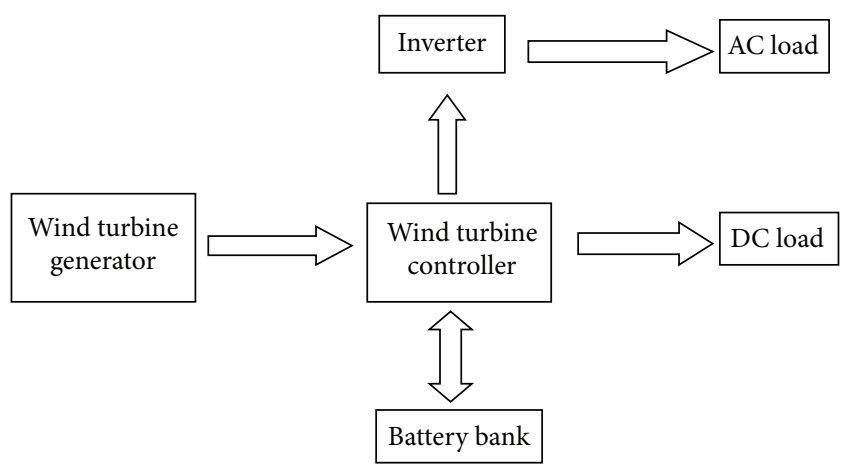

Figure 2: Schematic diagram of typical DSWES/SWES.

of the shroud has however a bearing on the cost of energy because it has significant increase in material, fabrication, transportation, and erection costs. This idea has among other factors impacted negatively the commercialization of ducted wind turbines. As is illustrated in this paper, it is not the cost of energy that has impacted negatively on the commercialization of ducted turbines.

\section{Materials and Method}

2.1. Decentralized Wind Energy Systems. A common decentralized power supply from small wind energy systems consists of wind electric generator, battery bank, inverter, wind turbine controller, control panels, interconnecting cables, and civil work. Two decentralized small wind energy systems are under construction. One of the systems is a common small wind energy system as explained above and is referred to as SWES in this paper. The other system is the ducted small wind energy system and is referred to as DSWES in this paper. Both systems have a $1 \mathrm{~kW}$ wind electric generator. The main difference between the two is that the DSWES has a shroud and its accompanying couplings which houses the wind electric generator. The shroud is being constructed from a $0.5 \mathrm{~mm}$ aluminium sheet. Figure 1 shows a DSWES shroud under construction. The construction and assembling is being done with the aid of our Science Workshop.

A schematic diagram of a common decentralized small wind energy system (DSWES/SWES) is shown in Figure 2.
TABLE 1: Materials and corresponding costs for the DSWES and SWES.

\begin{tabular}{lcc}
\hline Item & $\begin{array}{c}\text { DSWES } \\
\text { Cost (US\$) }\end{array}$ & $\begin{array}{c}\text { SWES } \\
\text { Cost (US\$) }\end{array}$ \\
\hline Wind turbine generator & 575.00 & 575.00 \\
Charge controller & 250.00 & 250.00 \\
Battery bank & 200.00 & 200.00 \\
Inverter & 115.00 & 115.00 \\
Tower and accessories & 50.00 & 40.00 \\
Aluminum sheets & 45.00 & - \\
Aluminum bars & 9.00 & - \\
Bearing & 5.00 & - \\
Bracket & 3.00 & - \\
Miscellaneous items (bolts, civil & 101.00 & 45.00 \\
works, cables, labour, etc.) & 1353.00 & 1225.00 \\
\hline Total & & \\
\hline
\end{tabular}

All the materials used to construct the DSWES/SWES were bought locally except the wind electric generators. The cost of these items was taken as part of the capital cost of the project as explained below. Table 1 shows the materials used for each system and the corresponding costs.

The technoeconomic analysis of wind turbines requires that the annual energy delivered by the wind electric generators be determined. The amount of electrical energy produced depends, among other factors, on the speed of the wind. Wind speed is site specific and depends on several geographical and climatic conditions. Wind resource assessment requires some considerable investment of time and money. In this study the mean annual wind speed obtained from our local weather station of $5 \mathrm{~m} / \mathrm{s}$ and the corresponding full load hours (number of hours in a year that the wind turbine operates at rated power) of 1900 hours were used. The rated power output of the wind electric generator was used to estimate the annual energy delivered by the SWES according to (3). To estimate the annual energy delivered by the DSWES, the results published by Matsushima et al. [11] were used with some modifications. They found out that their trial ducted turbine had an output power of 1.16 times that of a bare wind turbine when the turbine was allowed to yaw and 1.65 when the turbine was fixed. The average of the two, that is, 1.4 times, has been used in this paper.

2.2. Economic Analysis. Literature has alluded to the fact that ducted wind turbines' slow commercialization is due to the high cost of energy attributed to this technology. In this section calculations of the cost of energy of a ducted wind turbine and a bare wind turbine are shown, compared, and contrasted. Unlike in conventional power plants, the cost of energy in both DSWES and SWES is determined by two major components, namely, capital costs and operation and maintenance costs. Capital cost comprises the cost of the wind electric generator, wind turbine controller, battery bank, inverter, and miscellaneous (control panels, interconnecting cables, civil works, etc.) and for the DSWES it adds the cost of 
TABLE 2: Base values used for the comparison of the LUCE of the DSWES and the SWES.

\begin{tabular}{lcc}
\hline Input parameter & SWES & DSWES \\
\hline $\begin{array}{l}\text { Useful life of wind electric generator (years) } \\
\text { Useful life of wind turbine inverter and controller }\end{array}$ & 10 & 20 \\
(years) & 20 & 20 \\
Useful life of civil works (years) & 7 & 7 \\
Useful life of battery bank (years) & 0.02 & 0.04 \\
$\begin{array}{l}\text { Annual O\&M of DSWES/SWES as a fraction of } \\
\text { its capital cost }\end{array}$ & 0.10 & 0.10 \\
Discount rate as a fraction & & \\
\hline
\end{tabular}

Source: Nouni et al. [13].

the shroud (accessories and assembling). As shown in Table 1, the materials for the shroud and its assembling added $10 \%$ to the capital cost of the DSWES. Like any other industrial equipment both the DSWES and the SWES require operation and maintenance (O\&M) costs; these include the provision for repair and spare parts and maintenance of the electric installation. In this study, O\&M of the SWES were assumed to be $2 \%$ of the capital costs of the SWES, while $4 \%$ was assumed for the DSWES. Some of the assumed values are given in Table 2.

The comparison of the cost of energy of the DSWES and the SWES was done using the levelized unit cost of energy (LUCE). The following expression as suggested by Kandpal and Garg [12] was used:

$$
\mathrm{LUCE}=\frac{R_{\mathrm{wg}} C_{\mathrm{wg}}+R_{b} C_{b}+R_{\mathrm{ic}} C_{\mathrm{ic}}+R_{\mathrm{mis}} C_{\mathrm{mis}}+m_{o} C_{\mathrm{DSWES}}}{E},
$$

where

(a) $C_{\mathrm{wg}}, C_{b}, C_{\mathrm{ic}}, C_{\mathrm{mis}}$, and $C_{\mathrm{DSWES} / \mathrm{SwES}}$ are capital costs of wind generator, battery bank, inverter and controller, miscellaneous, and DSWES/SWES, respectively;

(b) $R_{\mathrm{wg}}, R_{b}, R_{\mathrm{ic}}, R_{\mathrm{mis}}$ are recovery factors for wind generator, battery bank, inverter and controller, and miscellaneous of the DSWES/SWES, respectively;

(c) $E$ is the annual electrical energy of the system, calculated according to (3).

The recovery factor $(R)$ is defined by

$$
R=\frac{d(1+d)^{T}}{(1+d)^{T}-1}
$$

where $d$ is the discount rate and $T$ is the useful lifetime.

The annual energy delivered by the wind electric generator is estimated by [13]

$$
E=\sum_{v \text { cut-in }}^{v \text { cut-out }} P(V) \mathrm{NH}(V)
$$

where $P(V)$ is electrical power output of the wind electric generator at a particular speed $V$ (as obtained from the power
TABLE 3: Estimated annual energy output and corresponding LUCE of the DSWES and the SWES.

\begin{tabular}{lcc}
\hline System type & $\begin{array}{c}\text { Annual energy output } \\
(\mathrm{kWh})\end{array}$ & LUCE (US cents/kWh) \\
\hline SWES & 1900 & 30 \\
DSWES & 2660 & 26 \\
\hline
\end{tabular}

curve of wind electric generator) and $\mathrm{NH}(V)$ is the number of hours in a year for which wind speed at the site was observed to be $V$ (as observed from wind speed frequency distribution curve of the site).

However, for this study, the rated power $(1 \mathrm{~kW})$ of the wind electric generators and the full load hours (1900 hrs) as explained above were used to determine the annual energy delivered by the bare wind turbine and the annual energy delivered by the DSWES is 1.4 times that of the bare wind turbine as explained in Section 2.1.

2.3. Technical Aspects. One important factor which is thought to have contributed to slow commercialization of ducted wind turbines is the immense wind loading on the duct during storm conditions [14]. Ducted wind turbines still need to meet engineering requirements to withstand wind loading in extreme wind conditions; that is, they must be able to resist overturning and bending during extreme wind speeds. FloDesign now known as Ogin had its test ducted wind turbine broken down in 2011 by the Hurricane Irene [15].

In high winds, conventional wind turbines "feather" away the blades to protect them from damage. This principle does not work in ducted wind turbines since the blades are housed in the duct. FloDesign after its disastrous experience has put flaps on the duct which close down in a storm [15]. It is still to be seen if it can stand the test of time.

The duct is of high solidity and has poor drag characteristics. This leads to poor response to wind direction changes. The ducted system can turn to face the wind direction but cannot accurately adjust itself if wind direction changes frequently in a short period [11]. Therefore, the concentrating effect will be difficult to achieve in this regard and renders the whole system ineffective.

\section{Results and Discussion}

The price of wind energy depends very much on the institutional setting in which wind energy is delivered. This is a key element to include in any debate about the cost of wind energy; however, this element falls away in this study because the institutional setting has been assumed to be the same for both systems. Table 3 shows the annual energy output and the corresponding LUCE of the DSWES and the SWES.

The study shows that the LUCE of ducted turbines compares favourably with that of bare wind turbines. At a wind speed of $5 \mathrm{~m} / \mathrm{s}$, the cost of energy from the DSWES is $13 \%$ cheaper compared to the SWES. This results from the output energy of the DSWES which is 1.4 times that of the SWES. 


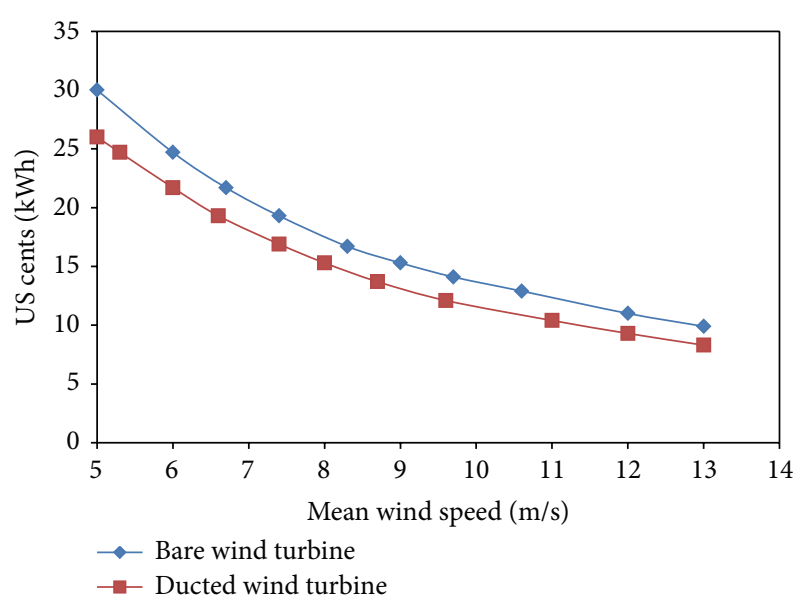

FIGURE 3: LUCE for the DSWES and SWES for varying mean wind speeds.

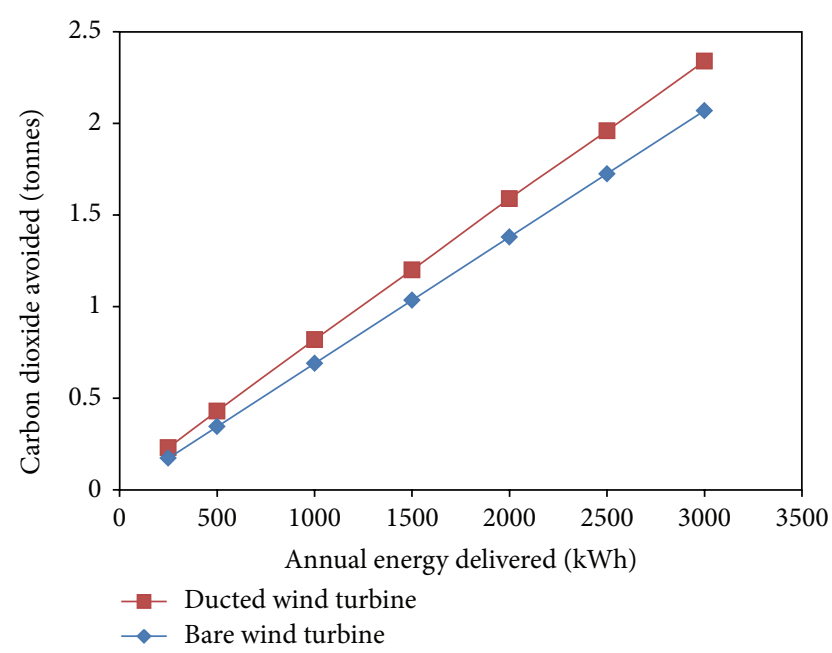

FIgURE 4: Annual carbon dioxide avoided from the DSWES and SWES for varying annual energy production.

The cost of wind energy varies with wind speed. Figure 3 shows the variation of the cost of wind energy with wind speed. In both cases, the cost of energy decreases with the increase in wind speed. The annual energy output in high wind speed areas is high and from (1) it is evident that LUCE decreases with increase in annual energy.

As shown in Table 3, the annual energy delivered by the ducted wind turbine is 1.4 times greater than the bare wind turbine. It follows that the amount of $\mathrm{CO}_{2}, \mathrm{NO}_{x}, \mathrm{SO}_{x}$, and water avoided is greater for the ducted wind turbine. Considering that wind energy saves $696 \mathrm{~g}$ of $\mathrm{CO}_{2}$ per kWh of electrical energy delivered [16] and factoring in the carbon price of $\$ 23$ per tonne of $\mathrm{CO}_{2}$ as suggested by the Clean Energy Regulator [17] makes the ducted wind turbine even more favourable. Figure 4 shows the variation of $\mathrm{CO}_{2}$ avoided with annual energy delivered. It clearly shows that a ducted wind turbine avoids more $\mathrm{CO}_{2}$ as compared to a bare wind turbine.
Producing electricity from wind energy reduces the consumption of fossil fuels and therefore leads to emission savings. As indicated above each $\mathrm{kWh}$ of electricity produced from wind avoids $696 \mathrm{~g}$ of carbon dioxide. Conventional power plants also emit nitrous oxides, sulphur dioxide, and methane. These wastes are freely dumped but generate costs for others in the form of lung diseases and damage from acid rain and global warming [18]. Producing electricity from wind also saves a lot of water. Conventional power utilities use millions of liters of water per day.

Current engineering cost models do not take these savings into account. They also do not consider disease risk reduction from wind energy. If all these factors could be considered the cost of energy from a ducted wind turbine will be even cheaper than that from the bare wind turbine because it avoids more carbon dioxide and saves more water, and its susceptibility to diseases reduction is higher.

The lack of state-of-the-art engineering techniques to protect ducted wind turbines in extreme wind conditions and the inability of ducted wind turbines to accurately follow wind direction changes are thought to have in a way contributed to the slow commercialization of ducted wind turbines.

\section{Conclusion}

The study has illustrated that the average LUCE of the ducted wind turbine is US $0.26 / \mathrm{kWh}$ compared to US $0.30 / \mathrm{kWh}$ of the bare wind turbine. The calculation did not take into account savings in $\mathrm{CO}_{2}$, wastes associated with conventional power production and their related external effects, and saved amount of water. Taking these factors into account would make ducted wind turbines even more favourable. It is regrettable that current engineering economic models do not take these elements into account. Failure of ducted wind turbines to penetrate the market is in part due to negative publicity as a result of the erroneous evaluation undertaken. Lack of appropriate engineering techniques to protect ducted wind turbines in extreme wind conditions and the inability of ducted wind energy systems to accurately follow the wind direction are also thought to have contributed to the slow commercialization of ducted wind turbines.

\section{Conflict of Interests}

The authors declare that there is no conflict of interests regarding the publication of this paper.

\section{References}

[1] REN21, Renewables Global Status Report:Update, REN21 Secretariat, Paris, France, 2009.

[2] M. Seitzler, "The electrical and mechanical performance evaluation of a roof mounted, one-kilowatt wind turbine," California Wind Energy Collaborative Report, University of California, Davis, Calif, USA, 2009.

[3] J. G. J. Oliver, G. Janssens-Maenhout, and J. A. H. W. Peters, Trends in Global $\mathrm{CO}_{2}$ Emissions Report, PBL Netherlands Environmental Assesment Agency, Ispara, Joint Research Centre, The Hague, The Netherlands, 2012. 
[4] S. Szewczuk and E. Prinsloo, Wind Atlas for South Africa (WASA): Project overview and current status, 2010.

[5] G. Munda and D. Russi, Energy Policies for Rural Electrification: A Social Multi-Criteria Evaluation Approach, UHE/UAB-10.01, 2005.

[6] G. M. Lilley and W. J. Rainbird, "A preliminary report on the design and performance of ducted windmills," Tech. Rep. C/T119, The British Electrical and Allied Industries Research Association, London, UK, 1957.

[7] S. J. Watson, D. G. Infield, J. P. Barton, and S. J. Wylie, "Modelling of the performance of a building-mounted ducted wind turbine," Journal of Physics: Conference Series, vol. 75, no. 1, Article ID 012001, 2007.

[8] G. Hassan and P. Jamieson, Beating Betz-Energy Extraction Limits in a Uniform Flow Field, Garrad Hassan and Partners Limited, Bristol, UK, 1999.

[9] G. J. W. Bussel, "The science of making more torque from wind: diffuser experiments and theory revisited," Journal of Physics: Conference Series, vol. 75, no. 1, Article ID 012010, 2007.

[10] D. G. Phillips, An investigation on diffuser augmented wind turbine deign [Ph.D. thesis], Department of Mechanical Engineering, School of Engineering, University of Auckland, 2003.

[11] T. Matsushima, S. Takagi, and S. Muroyama, "Characteristics of a highly efficient propeller type small wind turbine with a diffuser," Renewable Energy, vol. 31, no. 9, pp. 1343-1354, 2006.

[12] T. C. Kandpal and H. P. Garg, Financial evaluation of Renewable Energy Technologies, Macmillan Ltd., New Delhi, India, 2003.

[13] M. R. Nouni, S. C. Mullick, and T. C. Kandpal, "Technoeconomics of small wind electric generator projects for decentralized power supply in India," Energy Policy, vol. 35, no. 4, pp. 2491-2506, 2007.

[14] M. Shives and C. Crawford, "Ducted turbine blade optimization using numerical simulation," in Proceedings of the 21st International Offshore (Ocean) and Polar Engineering Conference, Department of mechanical Engineering, University of Victoria, Victoria, British Columbia, Canada, 2011.

[15] http://www.fastcompany.com/magazine/178/september-2013.

[16] J. Moccia, A. Arapogiani, J. Wilkes, C. Kjaer, and R. Gruet, "Pure power-wind energy targets for 2020 and 2030," EWEA Report, European Wind Energy Association, 2011.

[17] C. Munro, "The clean energy regulator," Annual Report 20112012, Commonwealth of Australia, Canberra, Australia, 2011.

[18] S. Krohn, P. E. Morthosrst, and S. Awerbuch, "The Economics of wind energy," A Report by the European Wind Energy Association, 2009. 


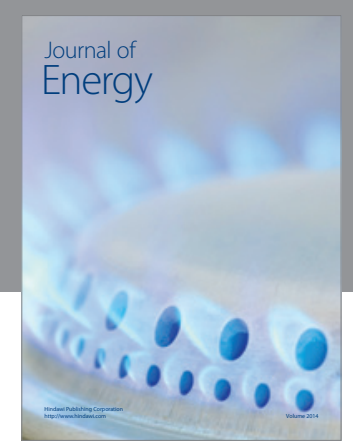

Journal of

Industrial Engineering
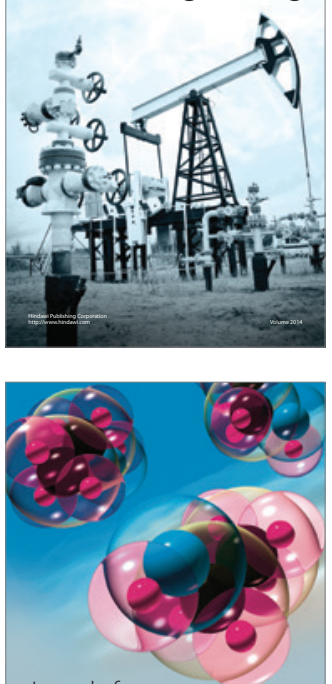

Fuels
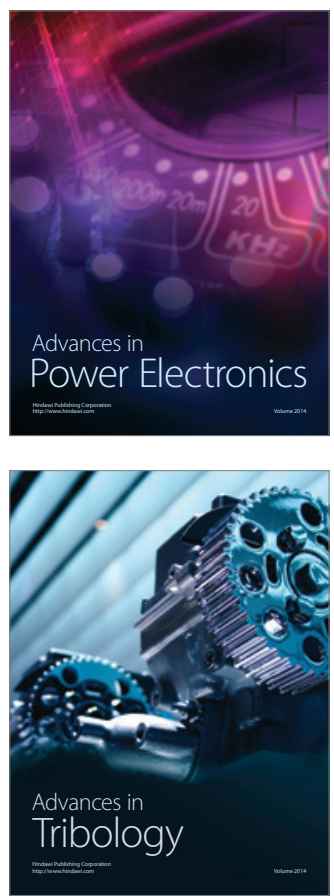

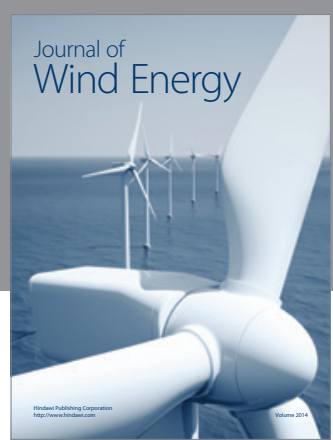

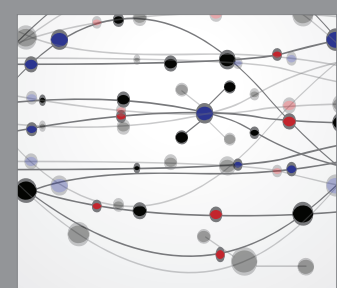

The Scientific World Journal

Submit your manuscripts at http://www.hindawi.com

Journal of

Structures
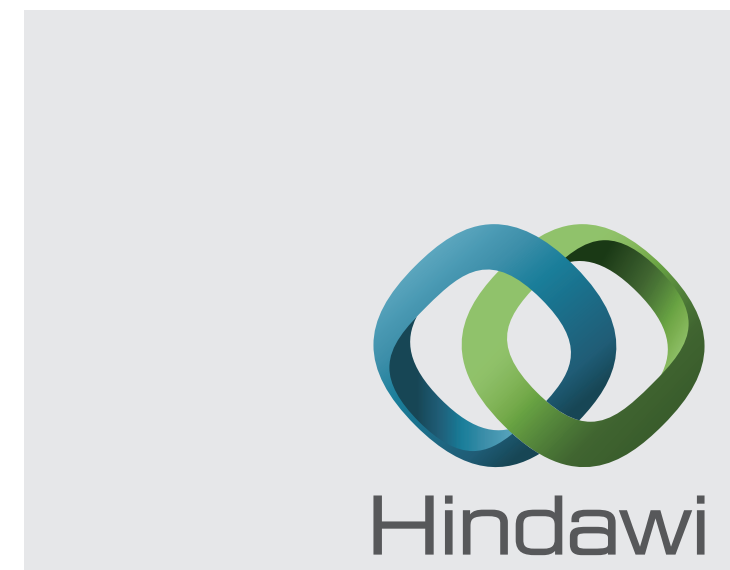

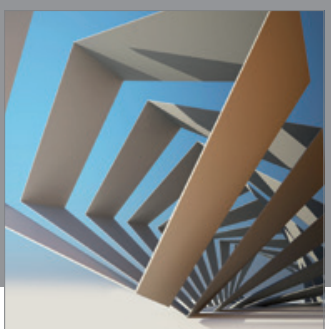

Rotating

Machinery
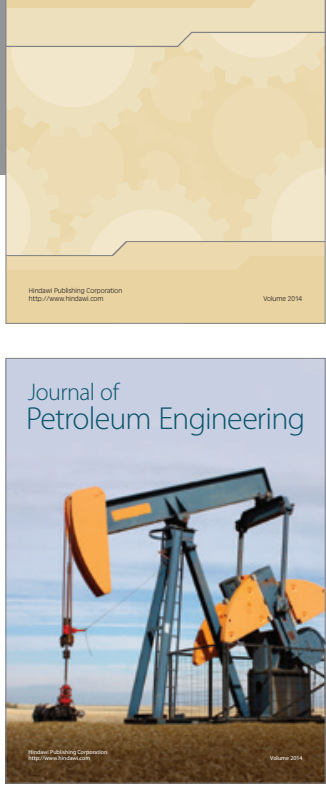

Journal of

Solar Energy
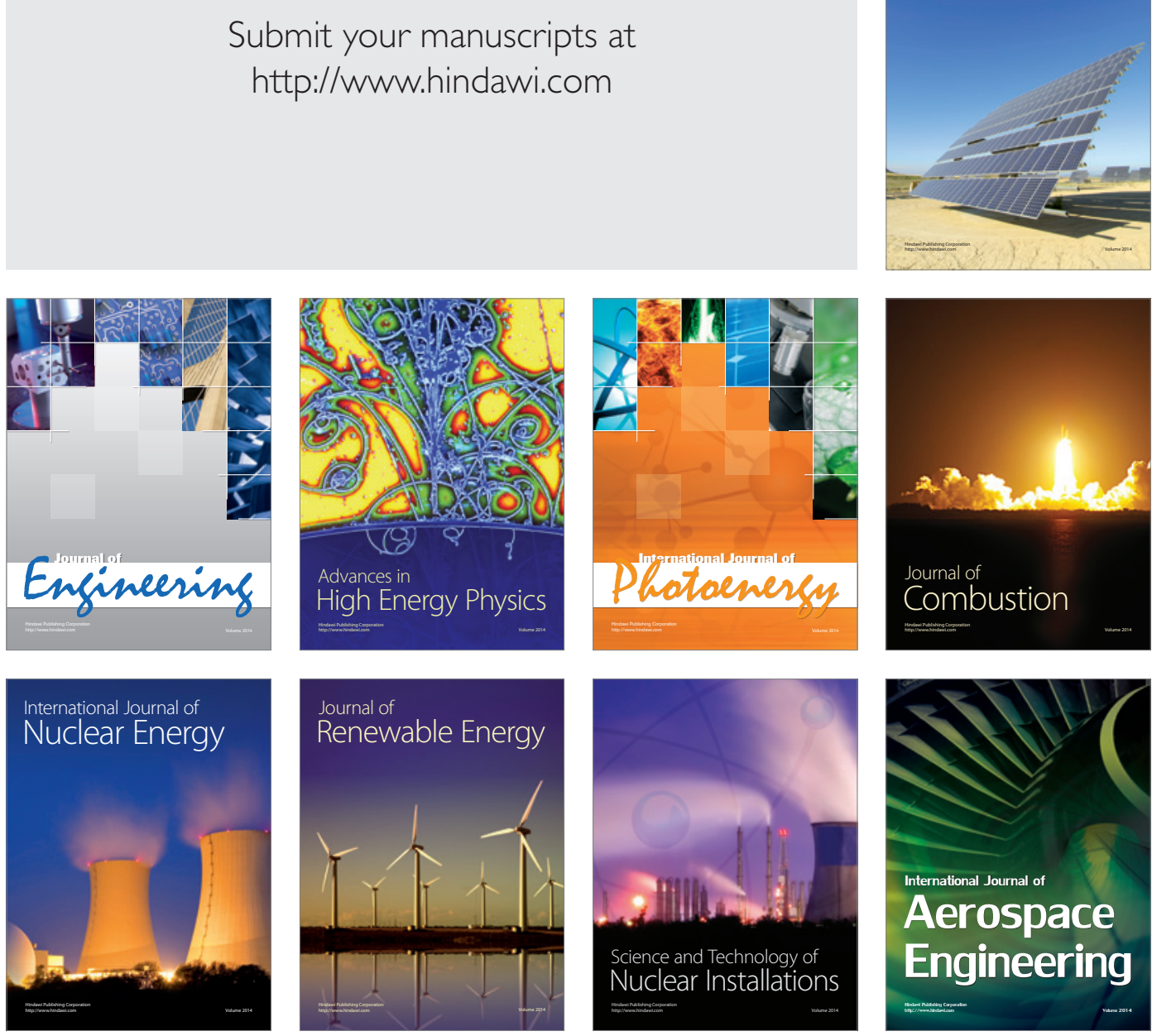